\title{
Identification of Maize Inbreds with High Levels of Maltose in Endosperm of Germinating Seeds
}

\author{
David B. Dickinson, John A. Juvik, and Janine R. Shaw ${ }^{1}$ \\ Department of Horticulture, University of Illinois at Urbana-Champaign, \\ 1103 West Dorner Drive, Urbana, IL 61801
}

Additional index words. Zea mays, Poaceae, sweet corn, sugary enhancer

Maltose appears in germinating seeds due to enzymatic hydrolysis of starch, but is absent or scant during development, except for endosperm of the sugary-1 (su-1) maize inbred IL677a and some related inbreds (Carey et al., 1984; Shaw and Dickinson, 1984). Mature dry seeds of these inbreds still contain some maltose ( $2 \%$ to $4 \%$ ). IL677a is also the source of sugary enhancer (se), which increases endosperm sucrose (Ferguson et al., 1978). We attempted to learn whether the unknown biochemical change causing maltose accumulation in developing endosperm also operates during germination. Entries included the starchy (Su) inbred B73, IL451b and 'Seneca Scout' (both $s u-1$ ), and the su1se inbreds IL677a and IL731a, which accumulate maltose during development (Shaw and Dickinson, 1984). Endosperms were dissected from seeds germinated in the dark under sterile conditions at $30 \mathrm{C}$ and moistened with $0.1 \mathrm{mM} \mathrm{CaCl}_{2}$, with 10 to 15 endosperms per sample, except for five to eight at 6 days due to limited seed supplies. Dissected tissue was kept on ice until ethanol extraction, and maltose was determined by gas chromatography (Shaw and Dickinson, 1984). Results of analyses sometimes varied; thus, data are presented as means over duplicates.

Maltose was consistently higher in IL677a than in the other inbreds (Fig. 1) and increased rapidly early in germination when the others had none or only trace amounts, reaching the highest level $(27 \mathrm{mg} / \mathrm{endo}-$ sperm) on the 4th day. An analysis of variance indicated the difference between IL677a and the other inbreds was highly significant

Received for publication 26 Feb. 1990. This work was supported in part by the Illinois Agricultural Experiment Station. The cost of publishing this paper was defrayed in part by the payment of page charges. Under postal regulations, this paper therefore must be hereby marked advertisement solely to indicate this fact.

${ }^{1}$ Current address: Dept. of Vegetable Crops, Univ. of Florida, Gainesville, FL 32611. at each germination time given in Fig. 1 ( $P$ $\leq 0.002$ ). IL677a had the smallest endosperm; thus, the difference would be even greater if maltose had been expressed as a percentage of dry weight. For example, dry weights at 4 days of germination were 84 , 123, and $250 \mathrm{mg} /$ endosperm for IL677a, IL451b, and B73, respectively. Results of Fig. 1 were confirmed and extended in another experiment, using seeds germinated 4 days. Two inbreds producing maltose during maturation had high maltose contents at 4 days (28 and $26 \mathrm{mg}$ /endosperm for IL677a and IL731a, respectively), while two lacking maltose during maturation had little (5.4 and $8.8 \mathrm{mg} / \mathrm{endosperm}$ for IL45lb and 'Seneca Scout', respectively); analysis of variance indicated a highly significant difference $(P$ $=0.0001$ ) between these two groups. In a third experiment, the high maltose of IL677a relative to IL451b was not reduced when endosperms from seed germinated 4 days were frozen quickly in liquid $\mathrm{N}_{2}$ after dissection and freeze-dried before extraction; thus, the differences reported above could not have arisen after dissection, which disrupts the tissue.

Enhanced breakdown of reserve polysaccharide due to higher than normal activity of $\beta$ - amylase is a likely cause of high maltose in IL677a and IL731a endosperm during germination and probably development also. Cereal grain $\beta$ - amylase arises in maturing endosperm, but activity is low until germination (Dure, 1960; Nishimura et al., 1987). Hence, the high maltose of IL677a and IL731a could be due to premature $\beta$ - amylase activation. Whether increased maltose is an aid or a detriment to germination, especially at suboptimal temperatures, remains to be established.

\section{Literature Cited}

Carey, E.E., D.B. Dickinson, and A.M. Rhodes. 1984. Sugar characteristics of sweet corn populations from a sugary enhancer breeding program. Euphytica 33:609-622.

Dure, L.S. 1960. Site of origin and extent of activity of amylases in maize germination. Plant Physiol. 35:925-934.

Ferguson, J.E., A.M. Rhodes, and D.B. Dickinson. 1978. Genetics of sugary enhancer (se) an independent modifier of sweet corn $(s u)$. J. Hered. 69:377-380.

Nishimura, M., I. Hara-Nishimura, D. Bureau, and J. Daussant. 1987. Subcellular distribution of $\beta$ - amylase in developing barley endosperm. Plant Sci. 49:117-122.

Shaw, J.R. and D.B. Dickinson. 1984. Studies of sugars and sorbitol in developing corn kernels. Plant Physiol. 75:207-211.

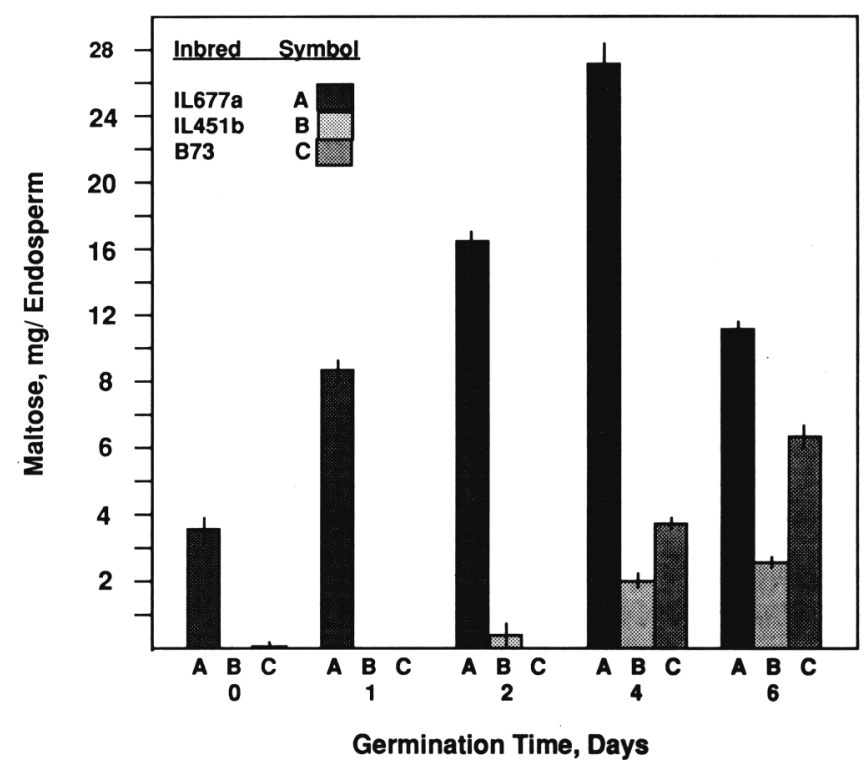

Fig. 1. Maltose content of endosperm from seeds germinated at various lengths of time. The vertical bars represent the range in concentration. 